\title{
O GRANDE TERREMOTO DE LISBOA E A IRRUPÇÃO DE UMA NOVA ORDEM SOCIOEDUCATIVA
}

\author{
Gisela Maria do Val ${ }^{1}$ \\ Julio Groppa Aquino²
}

\section{RESUMO}

O presente artigo, lastreado por algumas noções teóricas legadas por Michel Foucault, devota-se a descrever e analisar a emergência de uma nova ordem socioeducativa em Portugal após o terremoto de 1775, responsável pela reconfiguração do nexo poder-saber-verdade que havia pautado os modos de existência até então. A argumentação mobiliza um conjunto de documentos da época, por meio dos quais é possível testemunhar a constituição de uma nova arte de governar apoiada em estratégias educativas dos viventes. Assim, a ideia de população desponta como elemento central de um tipo de governamento operado pela propagação de uma racionalidade de base científica com propósitos educativos.

Palavras-chave: terremoto de 1755, população, governamento, educação.

${ }^{1}$ Universidade de São Paulo (USP), Faculdade de Educação (Feusp), São Paulo/SP, Brasil.

${ }^{2}$ Universidade de São Paulo (USP), Faculdade de Educação (Feusp), São Paulo/SP, Brasil. 


\title{
EL GRAN TERREMOTO DE LISBOA Y LA IRRUPCIÓN DE UN NUEVO ORDEN SOCIAL
}

\section{RESUMEN}

El presente artículo, basado en algunas nociones teóricas legadas por Michel Foucault, se dedica a describir y analizar el surgimiento de un nuevo orden social y educativo en Portugal después del terremoto de 1775, responsable de la reconfiguración del nexo poder-saber-verdad que había guiado los modos de existencia hasta entonces. Las discusiones movilizan un conjunto de documentos de ese período, a través del cual es posible presenciar la constitución de un nuevo arte de gobernar respaldado por estrategias educativas de los vivientes. Así, la idea de población surge como un elemento central de un modo de gobiernamiento llevado a cabo por la difusión de una racionalidad basada científicamente con propósitos educativos.

Palabras clave: terremoto de 1775, población, gobiernamiento, educación.

\section{THE GREAT LISBON EARTHQUAKE AND THE IRRUPTION OF A NEW SOCIAL ORDER}

\begin{abstract}
Grounded on some theoretical notions bequeathed by Michel Foucault, this article is devoted to describing and analyzing the emergence of a new socio-educational order in Portugal after the earthquake of 1775 , responsible for the reconfiguration of the nexus power-knowledge-truth that had guided the modes of existence until then. The discussions mobilize a set of documents from that period, through which it is possible to witness the constitution of a new art of governing supported by educative strategies of the living. Thus, the idea of population arises as a central element of a type of governing carried out by the dissemination of a scientific-based rationality with educational purposes.
\end{abstract}

Keywords: earthquake of 1775, population, governing, education.

\section{LE GRAND SÉISME DE LISBONNE ET L'IRRUPTION D'UN NOUVEL ORDRE SOCIAL}

\section{RÉSUMÉ}

S'appuyant sur des notions théoriques léguées par Michel Foucault, cet article est consacré à la description et à l'analyse de l'émergence d'un nouvel ordre socio-éducatif au Portugal après le tremblement de terre de 1775, responsable de la reconfiguration du lien pouvoir-savoir-veritè qui avait guidé les modes d'existence jusque-là. Les discussions mobilisent un ensemble de documents de cette période, à travers lesquels il est possible d'assister à la constitution d'un nouvel art de gouverner soutenu par stratégies educatives de les vivants. Ainsi, l'idée de population apparaît comme l'élément central d'un type de gouvernance reposant sur la propagation d'une rationalité fondée sur des bases scientifiques à des fins éducatives.

Mots-clés: séisme de 1775, population, gouvernement, education. 


\section{INTRODUÇÃO}

Lisboa, $1^{\circ}$ de novembro de 1755. Em convulsão, os elementos terra, água e fogo conspiraram para que o grande terremoto tivesse a envergadura de um apocalipse, resultando na destruição de grande parte da cidade e no desaparecimento de algo em torno de um a dois terços de seus habitantes. 3

A hecatombe começou pela terra, por volta das 9h45m. Depois de um rugido subterrâneo, houve um tremor "tão pequeno, que a poucas pessoas atemorizou [...]. Mas depois de hum intervallo de 30 até 40 segundos, o abalo foy taõ violento, que as casas principiaraõ a se arruinarem" (PEDEGACHE, 1756, p. 3).4 Os sobreviventes procuraram abrigo longe das edificações que ainda se mantinham em pé. Alguns correram para a margem do Tejo, a fim de escapar da chuva de destroços que tombavam nas ruelas da cidade de traçado labiríntico.

Entrava em cena o segundo elemento: a água. Sorvido por uma enorme voragem, o Tejo recuou, deixando nu seu leito. Logo depois, o rio precipitou-se, acompanhado pelas águas do mar, em ondas gigantescas e com uma velocidade jamais vista, segundo os relatos dos sobreviventes. As vagas ergueram-se em uma muralha que despencou para muito além dos limites do leito do rio, arrastando tudo que encontravam em seu caminho e aterrorizando "os pobres e já apavorados habitantes, que se puseram a correr de um lado para o outro com gritos horríveis [...] acreditando estar a dissolução do mundo próxima" (CARTA ANÓNIMA, 1990, p. 209).

Nas águas que afogavam a Baixa,5 misturavam-se pedaços de construções, corpos inertes e mastros entrelaçados. Assim, o “Téjo se converteo em breves instantes [...] em hũ horrorozo cemitério de cadáveres” (PEDEGACHE,

\footnotetext{
3 No que diz respeito tanto às mortes quanto ao horário exato em que o abalo teve início, não há coincidência entre os relatos do acontecimento.

${ }_{4}^{4} \mathrm{Na}$ transcrição das fontes, optou-se por manter fidelidade à grafia e à pontuação da época, tal como figuram nos documentos originais.

5 Região plana situada em um dos vales de Lisboa, à beira do rio Tejo. Após as intervenções arquitetônicas do marquês de Pombal, passou a ser conhecida como Baixa Pombalina.
} 
1756, p. 4), pois muitos dos que escaparam dos desabamentos agora vinham encontrar sua sepultura nas águas.

Apareceram, então, os clarões das primeiras chamas a anunciar o terceiro elemento: o fogo. Algumas testemunhas relataram que "se começou [...] a ver arder edeficios, em que as luzes, ou os fogoens das casas tinhão communicado o fogo aos madeiramentos" (MENDONÇA, 1758, p. 117-118); outras disseram que o ardor teve início em um palácio ao norte da cidade e que o vento noroeste o havia levado para o centro dela.

A quem avistava do alto, a cidade reduzia-se ao "mais horrível espetaculo das chamas que a devoravaõ cujo o claraõ allumeava, como se fosse dia, naõ só a mesma cidade, mas todo os seus contornos" (RATTON, 1813, p. 26). A maior parte da capital do Reino ardeu, consumindo-se por aproximadamente seis dias. Lisboa viu-se transformar em um cemitério de corpos insepultos, a exalar um odor fétido que assustava os sobreviventes.

Todo o centro da Cidade ficou reduzido a hum horroroso dezerto, em que senão vião mais que montes de pedras, e cumulos de cinzas, ficando somente algumas partes dos edeficios levantadas, denegridas do fogo (MENDONÇA, 1758, p. 123).

O terremoto de 1755 infligiu um rasgo brutal no cotidiano da capital portuguesa, convertendo-a em um cenário de devastação, onde todos, em maior ou menor grau, haviam perdido algo de valor. A tragédia desalojou costumes e práticas, desestabilizando todo um conjunto de regras de conduta e pondo em xeque os valores considerados mais naturais:

Pays deixavão os filhos; estes não se lembravão dos que lhes derão o ser. Os Esposos se esquecerão das Consortes. Não havia amigo para amigo. Ninguem fazia caso dos bens terrenos: só as vidas se procurava livrar (MENDONÇA, 1758, p. 116). 
Tratou-se, em suma, de um momento de revogação das balizas veridictivas de sustentação do presente, obrigando seus protagonistas a inventar estratégias de persistir existindo e, com isso, algum modo de racionalização do acontecido. Para alguns, a oscilação da terra, o avanço das ondas gigantes e o ardor do fogo retratavam o juízo final. Para outros, desacreditando que aquela desgraça seria obra de um Deus piedoso, tratava-se de uma tragédia natural.

A catástrofe ecoou por toda a Europa. À época, Lisboa, conhecida pela riqueza dos ornamentos de arte sacra e pela quantidade de igrejas e de conventos, era a quarta maior cidade do continente, depois de Londres, Paris e Nápoles. O tema do terremoto encontrou guarida, inclusive, no campo filosófico: Voltaire publicou, poucos meses depois do sismo, o poema Sobre o desastre de Lisboa e utilizou a tragédia como cenário de parte de seu livro Candido: o otimista; Rousseau redigiu a Carta sobre a Providência, discordando do posicionamento expresso no poema de Voltaire (GONZALBO, 2000); e também Kant, então um jovem pensador, dedicou ao terremoto três publicações, logo em 1756 (HERNÁNDEZ MARCOS, 2005).

Em Portugal, o desastre incitou imediatamente a procura por informações dentro e fora da capital, ao mesmo tempo em que aos poucos iam surgindo relatos de sobreviventes na forma de cartas (MENDONÇA, 1758; PEDEGACHE, 1756; CARTA ANÓNIMA, 1990; RATTON, 1813). Apesar da cidade praticamente destruída, as tipografias se reergueram por entre os entulhos, com vistas à divulgação de informações sobre o acontecido. Diversas oficinas tipográficas lisboetas recomeçaram suas atividades de imediato (CARVALHO, 1996), de modo que, mesmo em face das precaríssimas condições, o número de impressos que imediatamente vieram a público foi significativo.

De modo distinto das narrações produzidas pelas prensas remanescentes, o único periódico da cidade à época, a Gazeta de Lisboa, dedicou poucas menções à catástrofe. No dia 6 de novembro, publicou-se: "O dia $1^{0}$ do corrente ficará memorável a todos os séculos pelos terremotos e incêndios que arruinaram uma grande parte desta cidade; mas tem havido a felicidade de se 
acharem na ruína os cofres da fazenda real e da maior parte dos particulares" (GAZETA DE LISBOA, 1755a, p. 7). No dia 13 de novembro, mais uma nota:

\begin{abstract}
Entre os horrorosos efeitos do terremoto, que se sentiu nesta cidade no primeiro do corrente, experimentou ruína a grande torre chamada do Tombo, em que se guardava o Arquivo Real do Reino e se anda arrumando; e muitos edifícios tiveram a mesma infelicidade (GAZETA DE LISBOA, 1755b, p. 9).
\end{abstract}

As possíveis razões de tal laconismo foram investigadas por Belo (2000). $\mathrm{O}$ autor relembra o fato de que, com um número reduzido de exemplares, a Gazeta não se pautava exatamente pela difusão de informações locais, sendo que mais da metade de seu espaço era dedicada à reprodução de excertos de jornais estrangeiros. $\mathrm{O}$ autor também cogita a possível interferência da censura no que tange às notícias sobre a catástrofe.

Na trilha do pensamento foucaultiano (FOUCAULT, 2008) ao qual o presente estudo se afilia, torna-se possível especular que, mediante a súbita liberação das forças sísmicas, eclodiu uma desordem social sem precedentes, gerando uma espécie de vácuo político que, para ser equacionado, forçou um deslocamento acentuado das modalidades de condução das condutas. Assim, tal momento pode ser caracterizado como um acontecimento produtor de rupturas indeléveis, responsável por estabelecer novas relações entre os indivíduos, por suscitar confrontos e realocações discursivas, por desestabilizar as grades de inteligibilidade do presente e por ocasionar uma cacofonia dos jogos de veridicção; jogos estes que forçosamente se renovam no intuito de suprir lapsos veridictivos e demandas normativas ocasionadas pela dificuldade de governar.

Conforme afirma Farge (2002), o acontecimento é uma irrupção que gera discurso, ao mesmo tempo em que ilumina mecanismos anteriormente implícitos. Trata-se de uma eventualidade que estabelece novas práticas e, concomitantemente, dilui crenças e valores pregressos. Um acontecimento, nesse sentido, consubstancia um corte histórico que demanda estratégias outras para a 
metabolização do complexo e difuso movimento de governo dos corpos, das almas e das riquezas.

Destarte, a problemática surgida à época do terremoto lisboeta, qual seja, a necessidade de reconstruir uma cidade e, com isso, qualificar os sobreviventes para habitá-la, suscitou estratégias e práticas inauditas - e, vale frisar, de vocação educativa -, constituindo um jogo de forças cujo cerne implicava a produção e o controle da circulação da verdade. Esta é aqui compreendida na esteira das proposições de Foucault: não como aquilo que se definiria pela correspondência em relação aos fatos objetivos ou, mutatis mutandis, por sua refração àqueles tidos como falsos, mas, antes, como "um sistema de obrigações" (FOUCAULT, 2016, p. 13), cujos efeitos ganham eficácia apenas no horizonte de seu próprio uso. Uma verdade tão vigorosa quanto claudicante, por assim dizer, já que em situação de perene reconfiguração.

Tendo em mente tal horizonte, a presente investigação contemplou a imersão em diferentes fontes documentais, com o fito de analisar os efeitos veridictivos do acontecimento de 1755, bem como seus desdobramentos educacionais. Foi a partir do que ali foi narrado que os caminhos do estudo se delinearam. Assim, a construção do arquivo, mais do que um mero elemento da pesquisa, ocupou papel central no exercício analítico ora em tela: não cabia interpretar as fontes, mas deixá-las falar, permitindo que aflorasse a complexidade do que lhes era próprio.

A fim de assegurar tal imersão no arquivo, o primeiro passo investigativo implicou a incursão na literatura da época sobre o tema. Nessa direção, o estudo de Amador (2007) - sobre três coleções de textos referentes ao terremoto de 1755 que fazem parte dos acervos das bibliotecas e arquivos portugueses - revelou-se de grande valia. A autora apresenta uma descrição minuciosa das obras inseridas nas referidas coleções, as quais consistem em um 


\begin{abstract}
vastíssimo e heterogéneo conjunto de textos produzidos nas décadas subsequentes ao terramoto [...]. Pode-se mesmo afirmar que nunca antes deste acontecimento um cataclismo natural suscitara um tão grande interesse (AMADOR, 2007, p. 286).
\end{abstract}

Mediante a profusão de tais textos, as fontes eleitas pelo presente estudo concentraram-se em depoimentos e excertos de textos veiculados à época ou pouco depois do terremoto. Somaram-se a eles algumas manifestações de historiadores que se empenharam em estudar o cataclismo. Contudo, foi necessário ativar outro conjunto de fontes, a fim de compor um diagrama dos arranjos socioeducacionais pós-terremoto. Nesse novo grupo de documentos, destacam-se os dois principais antagonistas implicados na disputa sobre o primado interpretativo do desastre: Sebastião José de Carvalho e Melo, o futuro marquês de Pombal, e o padre Gabriel Malagrida. Da lavra de ambos, os textos selecionados foram: Memórias secretíssimas do marquês de Pombal e outros escritos, compilação de decretos, bilhetes e discursos editados pelo próprio ao final de sua vida e publicados originalmente em 1861; e Juízo da verdadeira causa do terremoto, que padeceo a corte de Lisboa no primeiro de novembro de 1755, opúsculo escrito por Malagrida meses depois da tragédia. Ainda, foram contemplados dois outros documentos. O primeiro deles, obra do padre Francisco José Freire, foi produzido dois anos após o desastre com o propósito de apresentar as providências adotadas à época: Memorias das principaes providencias, que se deraõ no terremoto, que padeceo a Corte de Lisboa no anno de 1755. O segundo, da autoria de António Nunes Ribeiro Sanches e impresso em Paris em 1756, é um tratado de saúde destinado a difundir as concepções científicas emergentes naquele período: Tratado da conservaçaô da saude dos povos, obra util e igualmente necessaria a os Magistrados, Capitaens Generais, Capitaens de Mar, e Guerra, Prelados, Abbadessas, Medicos, e Pays de Familias: com hum apêndix consideraçoins sobre os Terremotos, com a noticia dos mais consideraveis, de que fas mençaô a Historia, e dos ultimos que se sintiraô na Europa desde o 1 de Novembro de 1755.

Sanches foi um autor de destaque no que se refere às articulações 
efetuadas pelo Marques de Pombal no pós-terremoto; e seus escritos têm sido objeto de estudo de pesquisadores portugueses e brasileiros. No caso das pesquisas histórico-educacionais, a obra Cartas sobre a educação da mocidade de 1760 é a mais frequentemente referida. Já sobre o Tratado da conservação da saúde dos povos, há o artigo de Abreu (2013) que aborda uma série de tratados de medicina e suas contribuições ao saber médico do século XIX, assim como o artigo de Subtil e Vieira (2012) abordando as políticas higienistas na Europa a partir dos tratados de polícia.

O desastre e seus desdobramentos foram objeto de uma variedade de estudos, principalmente em Portugal, onde a literatura sobre o tema é ampla e detalhada. No Brasil, as referências ao desastre são mais pontuais e, em sua maioria, dele se valem como elemento coadjuvante para focalizar o período pombalino ou a atuação dos jesuítas. Por exemplo, em A longa viagem da biblioteca dos reis: do terremoto de Lisboa à independência do Brasil, de Schwarcz (2002), o sismo foi analisado como marcador histórico para a constituição da Biblioteca Nacional. Já a obra brasileira mais focal é $O$ mal sobre a terra, de Del Priore (2003), que, a partir de fontes diversas, analisa relatos de sobreviventes e reposiciona o papel político de D. José I.

A literatura sobre o assunto ganha densidade quando se soma a produção estrangeira (em inglês, espanhol e francês), abrangendo diferentes áreas do conhecimento, tais como medicina, filosofia, história, comunicação etc. Tal disseminação assinala o quanto o terremoto de 1755 povoou e ainda povoa o interesse dos pesquisadores.

Entre tais estudos, destaca-se o de Araújo (2006), o qual aborda a circulação das informações e o papel da imprensa europeia durante a divulgação do episódio. As providências tomadas no pós-terremoto são o mote do artigo de Marques (2016) em que são focalizadas as ações do setor eclesiástico. Já no texto de Midões (2009), a ênfase é dada à atuação administrativa e à comunicação do Estado. Boutaric (1998) também analisa as medidas tomadas após o sismo, realçando o problema do atendimento às vítimas, ao passo que Alves (2006), 
seguindo a mesma temática das diligências posteriores ao desastre, examina o inquérito pombalino (explicitado a seguir). A atuação do Marquês de Pombal foi analisada mais detalhadamente nos textos de Franco (2016) e de Santos (2011).

Ainda, duas coletâneas recentes sobre o terremoto foram publicadas: The Lisbon Earthquake of 1755: representations and reactions (BRAUN; RADNER, 2005) e História e ciência da catástrofe: $250^{\circ}$ aniversário do terramoto de 1755 (ROLLO, 2008) - ambas iniciativas reunindo autores oriundos dos mais diversos campos disciplinares, os quais situam o sismo como ponto de virada histórica dos padrões arquitetônicos, científicos, filosóficos e urbanísticos na segunda metade do século XVIII. Por fim, há um dossiê da revista Cuadernos Dieciochistas (DOSSIÊ, 2005), cujas abordagens versaram majoritariamente sobre os efeitos do cataclismo no território e na cultura espanhóis.

De modo distinto das abordagens usuais do terremoto de 1755, a investigação por nós conduzida centrou-se no próprio acontecimento e, mais especificamente, nos deslocamentos por ele efetuados, sobretudo quanto aos modos de vinculação dos sujeitos a uma nova política de verdade e seus insuspeitos efeitos subjetivadores; política, segundo nossa hipótese, viabilizada por estratégias de natureza educacional, precisamente.

Assim, o presente estudo debruçou-se sobre a maneira pela qual os modos de vida dos súditos portugueses, antes uma aglomeração quase informe de pessoas, acabaram por se constituir em um problema de governamento, ${ }^{6}$ angariando, assim, outro patamar político para a Coroa portuguesa. Para tanto, nossa argumentação alicerça-se na premissa segundo a qual não há modos de governar sem que as condutas dos sujeitos sejam indexadas a um conjunto de postulados reputados como verdadeiros (FOUCAULT, 2014a).

Desponta aqui o papel decisivo das intervenções portadoras de certa intencionalidade educativa como continente fático de produção, circulação e

\footnotetext{
${ }^{6}$ Optou-se, aqui, pelo emprego do termo governamento, diferentemente do genérico governo, uma vez que aquele comporta maior precisão conceitual (VEIGA-NETO, 2005).
} 
fixação de determinados enunciados, assim como, por extensão, de disputa em torno deles. No caso lisboeta, a educação7 dos súditos, por meio dos impressos que circularam à época, se nos afigura como uma estratégia basilar de governamento populacional, com vistas à sedimentação de um renovado nexo poder-saber-verdade.

A exorbitância dos números de mortos e as condições precaríssimas da cidade instavam atitudes improteláveis, as quais se consubstanciaram em iniciativas de controle da população remanescente, viabilizando seu assentamento em um espaço doravante planejado, organizado, arejado e limpo. Para tanto, era imprescindível que os súditos fossem instruídos a levar a cabo uma forma distinta de existência compartilhada.

A hipótese axial do presente estudo centrou-se, assim, na premissa de que o problema social e político foi, após o terremoto, não apenas o da reconstrução e o do repovoamento de uma cidade destruída, mas o das imperiosas mutações em torno da arte de governar derivadas da catástrofe, via determinadas práticas educativas em articulação com ações médicas e judiciais, com vistas à refundação do espaço-tempo de toda uma nação, cujos ecos não tardariam, presume-se, a surtir efeito nas colônias a ela ligadas.

\section{POMBAL E A RECONSTRUÇÃO DE LISBOA}

Sebastião José de Carvalho e Melo, futuro marquês de Pombal, foi o principal protagonista de uma transformação radical nas estratégias de administração da Lisboa setecentista. Buscando responder às necessidades de uma cidade e de um povo em situação caótica, sua atuação concentrou-se no âmbito logístico da circulação, entendido em sentido amplo: troca, contato,

\footnotetext{
7 A noção genérica de educação leva em conta a distinção oferecida por Noguera-Ramírez (2011), segundo a qual as práticas educacionais estariam atreladas a três diferentes matrizes históricas: a instrução entre os séculos XVII e XVIII; a educação liberal entre o XVIII e XIX; por fim, a sociedade educativa, vigente desde os finais do XIX.
} 
distribuição e deslocamento de pessoas, mercadorias, informações e saberes. Entra em cena a população como meio e fim de um novo modelo de condução das condutas.

Adotando um procedimento nada usual no Reino, que até então não dispunha de dados demográficos precisos, Pombal reuniu os dados sobre a catástrofe por meio de um inquérito enviado a todos os párocos de Lisboa, Lagos e Faro. O questionário continha 13 indagações sobre os detalhes do terremoto, tais como: hora de seu início e duração; quantidade de mortos e de edifícios destruídos; consequências materiais do maremoto e do incêndio; avaliação das medidas civis, militares e religiosas tomadas imediatamente após o desastre; e se houvera escassez de alimentos (ARAÚJO, 1987). Antes de tal iniciativa, os habitantes, em sua maioria, só possuíam o nome de batismo, já que "nunca nas suas vidas haviam tido que tratar com a administração" (CHANTAL, 1962, p. 45).

Segundo Dynes (2000), o terremoto de 1755 foi a primeira ocasião em que o Estado português chamou para si a responsabilidade de organizar uma resposta de emergência. Tal singularidade, projetada e supervisionada pelo então secretário Carvalho e Melo, consistiu em uma estratégia eficaz de administrar a multiplicidade populacional, de estabelecer seus pontos de fraqueza e de força, além de prescrever determinadas coordenadas e trajetórias das ações subsequentes.

Com vistas à propagação de seus ditames, ele se valeu da publicação de cartas e de editais. Por meio de decretos impressos em folhas avulsas distribuídas pela cidade e afixadas em locais estratégicos, regras e orientações eram divulgadas aos habitantes. Em um livro publicado três anos após o terremoto, em 1758, foram listadas as 14 providências adotadas. A saber:

PROVIDENCIA I. Evitar o receyo da peste, que ameaçava a corrupção dos cadaveres, sendo innumeraveis, e naõ havendo vivos para os sepultarem pela precipitada, e geral deserçaó dos moradores de Lisboa.

PROVIDENC. II. Evitar a fome, que necessariamente se havia de seguir, naõ só pelo motivo de naõ haver quem conduzisse os viveres; mas 
porque muitos Armazens delles havião sepultado as ruinas, e abrazado o incendio.

PROVIDENC. III. Curar os feridos, e doentes, que estavaõ desamparados nas ruas em perigo certo de morrerem.

PROVIDENC. IV. Reconduzirem-se os moradores de Lisboa, que haviaõ desertado, para se restabelecer a povoaçaõ, sem a qual nada se podia fazer.

PROVIDENC. V. Evitar os roubos, e castigar os ladrões, que haviaõ metido a saco a Cidade, despojando as Casas, e os Templos.

PROVIDENC. VI. Evitar que pelo mar se désse sahida aos roubos, e para esse effeito rondar o Rio.

PROVIDENC. VII. Remediar a necessidade, em que estava o Reino do Algarve, a Villa de Setubal, e os portos da America, e India.

PROVIDENC. VIII. Mandar vir algumas Tropas do Reino para servirem ao grande trabalho da Cidade, e seu socego.

PROVIDENC. IX. Darem-se as commodidades precisas para o alojamento interino do povo.

PROVIDENC. X. Restabelecer o exercido dos Officios Divinos nas poucas Igrejas, que se haviaõ salvado, ou em decentes accommodações interinas.

PROVIDENC. XI. Recolher as Religiosas, que vagavaõ dispersas, e darse-lhes a possivel clausura.

PROVIDENC. XII. Occorrer a diversas necessidades, em que estava o povo, as quaes por varias, e avulsas, se reduzem a huma classe separada.

PROVIDENC. XIII Actos de religião em S. Magestade para aplacar a ira Divina, e agradecer ao Senhor tantos benefícios.

PROVIDENC. XIV. Daõ-se os meyos mais conducentes para a reedificaçaõ da Cidade (FREIRE, 1758, s/p).

As medidas incidiam sobre a vida de todos e cada um dos sobreviventes.

Nas Providencias e nos decretos redigidos pelo próprio Carvalho e Melo, publicados em Memórias secretíssimas do marquês de Pombal (CARVALHO E MELO, s/d), é possível visualizar um panorama dos problemas então reputados como urgentes, assim como as repercussões educativas aí subjacentes.

Majoritário foi o espaço dedicado aos súditos e suas relações com o conjunto de forças do Reino, tais como saúde, cidade e comércio. Um tema essencial foi o retorno dos moradores a Lisboa, citado na Providencia $I V$ e 
sacramentado em um ofício de Carvalho e Melo datado de 3 de novembro: "Sendo S.M. informado da inteira deserção que tem abandonado a cidade de Lisboa aos efeitos da presente calamidade [...] manda ordenar [...] recolherem à cidade todos os seus moradores que Deus conservou vivos" (CARVALHO E MELO, s/d, p. 7779). Quase um ano após a tragédia, aos 28 de outubro de 1756, quando os habitantes planejavam fugir da cidade em razão do vaticínio de um novo terremoto, publicou-se uma medida para a contenção da debandada: "Mande fixar esta por edital nas portas da cidade, ordenando, que dela [Lisboa] não possa sair pessoa alguma nos dias 30 e 31 do corrente, e 1 de Novembro próximo seguinte, sob pena de prisão a arbítrio de S.M.” (CARVALHO E MELO, s/d, p. 108).

Além de assegurar a permanência dos lisboetas na cidade, era preciso garantir sua subsistência. Para tanto, o futuro marquês determinou "recolher os moleiros, padeiros e forneiros [...] e de lhes fazerem continuar os seus ministérios e o carreto do pão e mais comestíveis à cidade, na forma em que antes praticavam, sem demora" (CARVALHO E MELO, s/d, p. 72).

A saúde dos sobreviventes era também tema de grande preocupação, no intuito de evitar o retorno das epidemias que haviam sido recorrentes no passado recente do Reino. Também o problema do sepultamento dos cadáveres foi prontamente enfrentado, expresso na Providencia I e algumas vezes repetido nos avisos do Rei aos seus fidalgos: "passe a ocorrer ao desentulho das casas, que se acham em ruínas, de sorte que delas se possam extrair os cadáveres para se sepultarem, antes que a sua corrupção em toda a cidade produza outra calamidade" (CARVALHO E MELO, s/d, p. 73-74).

Outro movimento orquestrado pelo secretário de Estado foi a identificação dos vadios. Descrita na Providencia $V$, a iniciativa foi executada em duas fases. Primeiro ordenou-se uma investigação de reconhecimento dos desocupados; depois, determinou-se a pena: combater o ócio com trabalhos obrigatórios. 


\begin{abstract}
Desta feita, sou servido exercitar a inviolável e exacta observância dos regimentos e leis [...] ordenando que todos os corregedores e juízes do crime, cada um nos seus distritos, examine logo pronta e cuidadosamente, com a preferência a qualquer outro negócio, as vidas, costumes, e ministérios de todos os habitantes dos respectivos bairros e dos vagabundos e mendigos que neles forem achados com idade e saúde capaz de trabalharem: e que todas as pessoas que forem achadas na culpável ociosidade acima referida sejam presas, e autuadas em processos verbais, [...] sentenciados também verbalmente, impondo aos réus a pena de trabalharem com braga ${ }^{8}$ nas obras da mesma cidade a que têm dado um tão geral escândalo (CARVALHO E MELO, s/d, p. 88).
\end{abstract}

Como se observa no decreto acima, publicado já aos 4 de novembro de 1755, a convocação da polícia do bairro - diferentemente das tropas do Reino, conforme cita a Providencia VIII - não tinha a função de patrulhar, prender e enforcar ladrões, ou mesmo de vigiar os limites da cidade. Embora haja certa dificuldade de se estabelecer com precisão os limites de atuação da polícia à época, suas atribuições ganharam novas feições na gestão de Carvalho e Melo. Se antes ela era menos atuante e pouco vinculada aos habitantes, seu escopo, após a catástrofe, passou a incluir medidas de fiscalização social e ações preventivas de comportamentos considerados desviantes, por meio da manutenção da ordem e da coexistência pacífica dos habitantes (LOUSADA, 2003). A polícia atuava então como um aparato de integração dos indivíduos e de regulação da vida social.

A cidade destruída foi outra prioridade, aglutinando dois focos de atenção do futuro marquês: o primeiro foi a concretização de um plano urbanístico como cerne da mudança dos paradigmas político e econômico vigentes; o outro foi um modo de qualificar os habitantes de acordo com uma ideia de população condizente com a nova cidade.

Elaborou-se uma meticulosa disciplina arquitetônica, a qual conjugou os princípios sanitários - redes de água e de esgoto - ao imperativo da circulação de ar puro. Somam-se as técnicas de construção contra a queda de blocos em um

8 Argola de ferro ligada ao grilhão que prendia a perna dos condenados a trabalhos públicos (HOUAISS, 2009). 
possível colapso de edifícios, bem como a limitação do número de andares dos edifícios e o planejamento de ruas mais largas. Entrava em jogo o cálculo do risco. O único espaço que conservou a localização anterior ao terremoto foi o Terreiro do Paço, ${ }^{9}$ o qual, após intensa remodelação, passou a ser chamado oficialmente de Praça do Comércio, em homenagem à burguesia mercantil e à Junta do Comércio, organismo que suportou financeiramente os custos da reconstrução.

Nascia uma Lisboa marcada, em grande medida, pelos princípios inerentes à sociedade disciplinar, tal como descrita por Foucault (1987). A cidade idealizada por Carvalho e Melo almejava visibilidade e fácil circulação de pessoas, de mercadorias e, sobretudo, de verdades renovadas.

\begin{abstract}
[Lisboa] é ao mesmo tempo a última cidade antiga e a primeira cidade moderna. Última realização de um mundo de esquemas económicos centenários, ela oferece-nos também o primeiro exemplo de um novo pensamento técnico - e já nela se vislumbram princípios urbanísticos que permanecerão válidos durante duzentos anos, até a primeira metade do século XX. Os seus princípios racionais, ou antes, funcionais, os pormenores técnicos, são outras tantas afinidades com o urbanismo que o mundo industrializado porá em valor (FRANÇA, 1965, p. 98).
\end{abstract}

Pombal elegeu os problemas prioritários e racionalizou as intervenções governamentais, com vistas à gestão dos fenômenos atinentes à maximização das potencialidades da população sobrevivente. Desse modo, a soma dos súditos passou a ser considerada um elemento primordial na logística do Reino. O comando da monarquia portuguesa, para além da soberania de seu território, incorporava então mais um elemento sob seus cuidados: a população. Tratava-se, assim, de estabelecer estratégias para agir sobre os hábitos, os temores e as demandas desse novo personagem político-social.

Desta feita, é possível afirmar que, no país ibérico posterior ao terremoto, irrompeu uma nítida transição das artes de governar. As ações do governante

\footnotetext{
9 Praça localizada na região da Baixa junto ao Rio Tejo, onde se encontrava o palácio real destruído no terremoto.
} 
começaram a abranger, além das interferências centralizadas no território, uma intervenção mais contundente nos habitantes, não mais considerados somente no âmbito da quantidade, mas, sobretudo, no da sua produtividade. Assim, a cidade e seus habitantes assumiram posições análogas e complementares nos cálculos político-veridictivos de então.

\section{O EMBATE PELA VERDADE}

No processo de refundação da cidade e de seus habitantes, a circulação de informações operou como estratégia educativa fundamental, firmando-se como meio de validação das explicações para o terremoto. Determinar uma causa natural para o cataclismo significava a chance de um recomeço sem o peso da culpa cristã e de sua posterior prostração penitencial. Pela via da propagação de enunciados sustentados cientificamente, cuja circulação foi amplamente incentivada por Carvalho e Melo, firmava-se uma abordagem racional do sismo, classificando-o como fenômeno natural passível, inclusive, de se repetir periodicamente. Um novo campo veridictivo estava a se descortinar, baseado, sobretudo, nas ideias de segurança e de risco, bem como nos fazeres replicadores das instituições, especialmente aquelas ligadas à medicina.

O texto de António Nunes Ribeiro Sanches, Tratado da conservaçaô da saude dos povos..., traz em seu apêndice interpretações técnicas sobre os vapores e as exalações do interior da Terra como fatores preponderantes para a eclosão do terremoto:

Hoje hum eclipse da Lua ou do Sol naõ nos atemoriza, por que sabemos a cauza; as naçoins, que à naô conheçem ainda, e aquellas que à ignoraraõ nos tempos passados, tinhaõ estes fenomenos por prodigios, e por castigo do ceo [...]. Se soubéssemos taôbem a cauza dos Terremotos, como a sabemos dos ventos, das trovoadas, e dos trovoins, naõ teriamos, pode ser, estes notaveis movimentos da Natureza por castigo do ceo, nem tirariamos deles prognosticos para a nossa total ruina (SANCHES, 1756, p. 262-263). 
Para além da explicação do sismo em bases científicas e do rechaço às explicações místicas, o tratado de Sanches oferece um compêndio de preocupações médicas, apresentando a particularidade de tratar pela primeira vez a saúde na esfera pública, como ressalta o autor: "Ate gora parece que esta sorte de Medicina Politica naô entrou, como devèra, na cosideraçaô do Tribunais da Europa" (SANCHES, 1756, p. VII). Interessava ao médico português atrair o interesse governamental para a "necessidade que tem cada Estado de leis, e de regramentos para preservar-se de muitas doenças, e conservar a Saude dos subditos" (SANCHES, 1756, p. VI).

Outra singularidade desse tratado foi a de eleger como seus interlocutores imediatos os magistrados, os arquitetos $\mathrm{e}$ os médicos. Prescrevendo uma série de normas para a implementação de espaços salubres, o autor reflete: "[...] me pareçeo que ja mais se consultaraô os Medicos, nem pello Magistrado, e muito menos pellos arquitectos, para fundar qualquer povoação" (SANCHES, 1756, p. 48). O médico setecentista discorreu sobre as técnicas e precauções necessárias para edificar, reformar, construir e planejar os edifícios de uma cidade - igrejas, conventos, hospitais, prisões e casernas -, com ênfase na observância da conservação da qualidade do ar, bem como dos perigos da umidade.

Para Sanches, as ruas eram repositórios das imundícies dos animais e também daquelas oriundas dos próprios habitantes; local onde se lançavam "esterco, cascalho, calcinas, borras devinho, azeite, bagaços, ou outra qualquer couza fetida e hedionda" (SANCHES, 1756, p. 80). A fim de combater tamanha desordem, Sanches vislumbrou ruas projetadas de modo que os ventos as livrassem de exalações maléficas: ruas largas, retas e "cubertas primeyramente de cascalho, greda, carvaô em pó, pedras de cantaria, e taô grandes que possaô resistir por muitos annos a agitaçaô dos animais, e a ò pezo dos carros, e carretas" (SANCHES, 1756, p. 77).

Para tanto, fazia-se necessário que houvesse uma "ley inviolavel que cada morador tivesse limpa cada dia pella manhaâ a fronteira da sua caza, que nemhuâ 
sorte de estado, nem ainda Ecclesiastico ficaria isento desta o brigaçaô" (SANCHES, 1756, p. 78-79). Ademais, deveriam ser despachados para os arrabaldes da cidade todos

os carniçeiros que degollaô, os tripeyros, cortidores, os que fazem vellas de sebo, os louçeyros que vidraô louça com chumbo, e outros minerais pestilentes, os que lavaô, e trabalhaô e fabricaô as lans; os que vendem peyxes salgados, queijos (SANCHES, 1756, p. 80).

Se, por um lado, a tragédia lisboeta foi responsável pela criação de um dos primeiros tratados higienistas europeus, por outro, circulavam concomitantemente interpretações da calamidade que insistiam em atribuir sua causa à cólera divina. Seus defensores preconizavam as preces e os deveres espirituais antes de qualquer trabalho mundano, impingindo aos pecadores a conversão e a penitência com o intuito de aplacar a ira divina. Mostra maior disso é o Juizo da verdadeira causa do terramoto que padeceo a corte de Lisboa no primeiro de novembro de 1755, texto escrito pelo padre Gabriel Malagrida em janeiro de 1756.

O padre inaciano foi o religioso preferido dos pais de D. José I, regente à época do terremoto. De posse de livre trânsito na Corte e de grande influência sobre o monarca e sua família, Malagrida foi o confessor e conselheiro espiritual da realeza. Assim está descrito em uma de suas biografias:

Trinta annos de apostolado no âmago das florestas do Novo-Mundo, entre povoações selvaticas do Maranhão e nas vastas dioceses do Brazil; dez annos mais consumidos a prégar a cruz de Jesus Christo ao povo e á côrte de Lisboa; e, depois, como galardão d'esses quarenta annos de serviços aos interesses de Portugal e da Igreja, uma condemnação iniqua pronunciada em nome de Portugal e da Igreja, por juizes sem consciencia, nem auctoridade; e, finalmente, apoz trez annos de incomportaveis angustias, nos humidos subterraneos da Torre de S. Julião, a morte do martyr na ultima fogueira da Inquisição portugueza, accendida por ordem e sob as sugestões do marquez de Pombal: eis o resumo da existencia de Malagrida (MURY, 1875, p. XXVII). 
Reputado como exímio orador, Malagrida proferia seus sermões com requintes cênicos a uma vasta audiência. Desse modo, alimentava a contrição dos ouvintes, valendo-se de uma linguagem que ultrapassava as palavras: "se a penitencia exterior o deliciava, mais saborosa lhe era a mortificação interior de todos os affectos, a abnegação da vontade propria” (MURY, 1875, p. 9). Sua pregação era o meio de difusão de sua doutrina, segundo a qual as preces e penitências eram as únicas formas de arrependimento e de misericórdia.

Tal movimento concorria diretamente com as medidas de Carvalho e Melo, de modo que providenciar alimentos, evitar o abandono da cidade ou coibir crimes representavam futilidades heréticas aos ouvidos dos mais devotos. Para Malagrida, a retirada dos escombros e os planos de reconstrução da cidade eram uma clara provocação aos desígnios divinos. O padre conclamava, em seus sermões e escritos, a alma dos fidalgos, alegando que eles deveriam se ocupar exclusivamente com a meditação e o arrependimento.

O diário do padre Eckart, escrito em uma prisão portuguesa em 1791, apresenta uma carta do padre Malagrida ao companheiro de ordem religiosa:

Tendo-se espalhado vários folhetos pela cidade de Lisboa, que, pondo de parte qualquer intervenção da Providência, atribuíam o terramoto apenas a causas naturais, e não havendo ninguém que se atrevesse a contradizer tão temerárias e ímpias afirmações, eu, o menor de todos, desci à arena, tomei a pena e, apoiado no testemunho de muitos Santos Padres, demonstrei que este terrível tremor de terra era sinal claro da ira de Deus. Isto desagradou de tal modo ao Primeiro Ministro Carvalho e Melo, que me expulsou da cidade para o colégio de Setúbal (MALAGRIDA apud ECKART, 1987, p. 23).

A atitude de tomar a pena, narrada pelo jesuíta, concretizou-se no texto que o próprio Malagrida entregou a D. José I e a muitos fidalgos. Seu conteúdo certificava que a catástrofe que se abatera sobre Lisboa era um castigo dos céus em razão dos pecados do povo português. Assim inicia-se o escrito: 
Sabe pois, oh Lisboa, que os unicos destruidores de tantas casas, e Palacios, os assoladores de tantos Templos, e Conventos, homicidas de tantos seus habitadores, os incendios devoradores de tantos thesouros, os que as trazem ainda taõ inquieta, e fora da sua natural firmeza, naõ saõ Comentas; naõ saõ Estrellas, naõ saõ vapores, ou exhalaçoês, naõ saõ Fenomenos, naõ saõ contigencias, ou causas naturaes; mas saõ unicamente os nossos intoleraveis peccados (MALAGRIDA, 1756, p. 34).

Opondo-se frontalmente à atribuição de causas naturais ao terremoto, o gesto evocado pelo padre foi o da responsabilização conjunta dos habitantes pela conduta herética dos sobreviventes e moribundos: "não sei como se possa atrever hum sujeito Catholico a attribuir unicamente a causas, e contigencias naturaes, a presente calamidade deste taõ tragico terremoto?” (MALAGRIDA, 1756, p. 8).

Ao vincular o sobrevivente à verdade do castigo divino, Malagrida tentava persuadir os fiéis, modificando a relação de cada um para consigo mesmo. As penitências prescritas - "pés descalços, cruzes, açoutes, jejuns a paõ e agua" (MALAGRIDA, 1756, p. 28) - intimavam igualmente a "attender ao Padre Director” (MALAGRIDA, 1756, p. 29). O texto finaliza com uma demonstração de quão incansável deveria ser uma vida devotada à eternidade:

Quantas pessoas nobres, e ilustres haverá, que naõ se sabem examinar! Quantas que naõ se sabem confessar! E quantas que naõ se sabem arrepender, e cuidaõ que toda esta fabrica he negocio de palavras, he bater no peito, he rezar o formulário do Acto de contriçaõ, e nada mais, e quantos que naõ pódem absolver; porque, ou naõ sabem, ou estaõ esquecidos, até dos mesmos Artigos de Fé! Prouvera a Deos, que isto fosse só hum caso singular, e que naõ tivesse achado, similhante desamparo, ainda em pessoas muito conspicuas! Como se pódem facilitar, e capacitar estes a fazer uma confissaõ geral, canonica, verdadeira, e segura, se não nestes silencios, e solidoens, á luz de tantas instrucçoếs, e meditaçoens, onde ainda com assistencia de Mestres taõ conspicuos, e taõ idoneos para este fim, padecem suas duvidas, para o socego da sua consciencia, para acertar os meyos, que haõ de tomar, e o norte que haõ de seguir para assegurar o negocio da sua salvaçaõ (MALAGRIDA, 1756, p. 30-31). 
$\mathrm{Na}$ outra ponta do espectro das forças discursivas atuantes então, as providências do secretário de Estado operaram no sentido de impulsionar os moradores a se responsabilizarem pela reconstrução da cidade, por meio de tecnologias de base científica capazes de minimizar os efeitos de novos possíveis tremores. Nesses termos, Carvalho e Melo oferecia também uma proposta de salvação, só que desfrutável na própria vida terrena.

Cada um dos vértices desse embate pela verdade conduzia os sobreviventes a modos de existência regulados por determinada ideia de verdade. Ambos, porém, estavam acoplados à ideia de revelação: em um caso, espiritual; no outro, científica.

$\mathrm{Na}$ batalha dos dois antagonistas pela primazia veridictiva, dois movimentos fundamentais despontam: de um lado, a convocação de uma ação dos indivíduos, criando direitos e deveres em relação a si, aos outros e, sobretudo, à cidade; de outro, o reconhecimento e a obediência a padrões e valores já sedimentados. Nenhum dos dois vetores atuava exclusivamente; antes, operavam de modo concomitante, pois, ao se aderir a tal ou qual conjunto de verdades, criava-se o liame ético de certo assentimento, a partir do qual os indivíduos adaptavam suas condutas, seus valores e suas demandas.

Os planos previstos por ambos os antagonistas coincidiam em alguns pontos, mas seus procedimentos eram distintos. O padre atuava como um perfeito pastor de rebanho, devendo guia-lo diuturnamente, além de promover constantes convocações por meio dos sermões. Se a abordagem individualizante efetivava-se pela direção de consciência de seus devotos, a aproximação aos cristãos mais distantes consubstanciava-se por meio da pregação, tendo sido esta o meio principal da atuação do clérigo.

Na outra ponta, urgências específicas povoavam as preocupações do futuro marquês. A construção de uma cidade ressurgida das cinzas demandava a refundação dos usos e costumes da população sobrevivente. Carvalho e Melo carecia alcançar, o mais rápido possível, a maior parte dos indivíduos. Assim, a utilização dos impressos não parece ter sido uma estratégia aleatória. Apesar de 
o padre também fazer uso da prensa para propagar seu discurso, Pombal foi um expoente no mecanismo da circulação dos impressos. Ele arrebanhou alguns escritores e outros fiéis colaboradores, no intuito de fornecer notícias regulares sobre a política de proteção às pessoas afetadas pelo terremoto e sobre a reconstrução da cidade (FALCON, 1993).

Para além da inferência imediata a que tal procedimento aponta - ou seja, o approach propagandístico -, o que circulou nos impressos eram peças constitutivas de uma engrenagem veridictivo-educativa conexa a outro modo de racionalização da experiência cotidiana. Assim é que os impressos de Carvalho e Melo propagaram convocações, ordens e providências, disseminando atitudes e procedimentos incitadores de um novo sujeito histórico. Prova disso é o fato de que a versão naturalista da catástrofe foi constituída com tamanha veracidade, que ela permaneceu quase intacta até os dias atuais.

A querela entre o padre e o secretário foi longa. Logo após a publicação do texto de Malagrida, Carvalho e Melo logrou obter o desterro do religioso para Setúbal, apoiando-se no argumento de que a propagação de seus escritos contribuía para aumentar a perturbação e a dispersão dos habitantes de Lisboa.

Como reação, o padre bradou do púlpito contra Carvalho e Melo. Dado a pressentimentos e visões, o jesuíta teve um presságio que envolvia D. José I, advertindo-o que a vida deste corria perigo. Em 3 de setembro de 1758, homens encapuzados abriram fogo contra a carruagem do monarca, ferindo-o no ombro, no braço direito e nas costas.

Por três meses fez-se silêncio na Corte. A tentativa de assassinato foi ocultada, e a Rainha assumiu a regência, disseminando a versão de que o rei havia se acidentado. Em dezembro do mesmo ano, foram sentenciados por regicídio alguns membros das famílias nobres mais tradicionais de Portugal: os Távora, os Atouguia e os Aveiro. Os homens foram presos; as mulheres e as meninas, transferidas para mosteiros; e os meninos, levados para colégios internos (SANTOS, 1979). O processo correu rapidamente, e, aos 12 de dezembro, todas as sentenças haviam sido lavradas. No dia seguinte, Dona Leonor, a marquesa de 
Távora, foi decapitada, assim como dez homens foram supliciados com requintes de tortura, sendo cinco deles nobres da mais alta estirpe, entre os quais estava Dom Francisco, o marquês de Távora (LEAL, 1874).

O caráter improvável da ocorrência não foi o uso de suplícios como pena, o que era prática comum da Inquisição portuguesa e, portanto, usual para os lisboetas. Sua raridade deveu-se à procedência social dos condenados. Degolar, supliciar e queimar representantes da alta aristocracia transformou o ordinário em um acontecimento absolutamente inusitado aos olhos e ouvidos da época.

Junto com os nobres, os jesuítas também foram acusados de tramar contra a vida do Rei, tendo sido encerrados sem qualquer contato com o mundo exterior. Por meio de articulações, lutas, ameaças e acordos, em 3 de setembro de 1759 todos os membros da Companhia de Jesus foram expulsos de Portugal, incluindo aqueles vindos do Brasil, segundo a lei assinada por Carvalho e Melo, agora conde de Oeiras.

Malagrida foi aprisionado em janeiro de 1759, sentenciado por lesamajestade, conluio e autoria. Encarcerado nas masmorras do Forte da Junqueira, ${ }^{10}$ não foi levado ao cadafalso com os outros condenados, nem expulso como os demais padres de sua ordem, mas transferido para os cárceres do Santo Ofício. E, assim, "quasi nu; havia vinte e oito mezes que não mudara de roupa branca; a sua roupeta era um apontuado de trapos" (MURY, 1875, p. 171), compareceu diante dos inquisidores. Acusado de heresia, blasfêmia e falsas profecias redigidas em dois textos redigidos na masmorra, foi condenado "a ser garrotado pela mão do algoz, e queimado na Praça publica de Lisboa” (MURY, 1875, p. 177). Aos 21 de setembro de 1761, o auto-de-fé foi promovido com toda a solenidade. Pela derradeira vez, a justiça eclesiástica condenava um homem à morte.

${ }^{10}$ Localizado em frente ao Rio Tejo, foi construído em 1649 a fim de reforçar a defesa da cidade. À época do reinado de D. José I, foi utilizado como prisão, tendo sido demolido em 1940 (ARAÚJO, 1939). 
O espetáculo funesto ocorreu na Praça do Rossio:11 o padre percorreu um circuito de círio fúnebre ladeado por dois monges beneditinos. Estava ele "com as mãos atadas para as costas, e um freio de páu na bocca" (MURY, 1875, p. 179), usado para calar os hereges. Depois da leitura das condenações, foi garroteado pelo carrasco. Seu corpo foi queimado até as cinzas, e estas, jogadas ao mar.

\section{A EDUCAÇÃO DOS SÚDITOS}

No embate entre as modalidades de produção da verdade, naquele momento, o presente triunfaria sobre o passado, conforme afirmou Pombal no Discurso politico sobre as vantagens que o Reino de Portugal pode tirar da sua desgraça por ocasião do terramoto do $1^{\circ}$ novembro de 1755: "quando o povo perdeu a norma dos seus antigos costumes, digo que as melhores leis não acham em que pegar: é preciso então, para me explicar assim, é necessário um golpe de raio, que abisme e subverta tudo, para tudo reformar" (CARVALHO E MELO, s/d, p. 188).

Impressos versus sermões, circulação versus estagnação, ciência versus misticismo. Naquele duelo entre vida e morte, em que cada um guerreava em prol de sua visão de mundo, produziram-se marcas profundas, contestaram-se evidências, inverteram-se sentidos.

No itinerário propiciado pela imersão nos documentos mobilizados no presente estudo - compreendidos como "peças da dramaturgia do real" (FOUCAULT, 2006, p. 206) -, o leitmotiv que percorre a trama lisboeta pósterremoto aponta para o nascimento da ideia de população, e esta invariavelmente atrelada a práticas de cunho educativo, com vistas à sedimentação da nova racionalidade em voga. Para além da lógica que vinculava o número de súditos ao poderio da monarquia, agora entrava na pauta a

\footnotetext{
${ }^{11}$ Praça de Lisboa localizada na Baixa na qual, antes do terremoto, se situava a Casa de Despacho da Santa Inquisição.
} 
regulação das almas e dos corpos por intermédio da gestão políticoadministrativa do Estado, com vistas ao incremento de uma coexistência produtiva por parte dos sujeitos.

A ideia de população desponta, assim, como uma massa passível de ser gerida segundo determinados princípios racionais disseminados entre os súditos. $\mathrm{Na}$ tentativa de identificar os pontos a partir dos quais se foram formulando as diretrizes que nortearam a emergência da noção de população e sua gestão, três domínios de governamentalização social entrelaçaram-se: a medicina preventiva, o urbanismo e a educação.

No primeiro caso, tratou-se de uma operação suplementar à exigência de reconstrução da cidade, tendo como alvo a vitalidade dos sobreviventes. Mais do que atender os feridos, a medicina que se organizou no tratado de Sanches pautou-se no primado da prevenção e do aprimoramento da saúde coletiva problemática até então pouco explorada pelos governantes. Tal abordagem centrava-se na noção de risco, fosse dos vapores e das exalações insalubres, fosse dos perigos que afetavam a água e o solo. Assim, reclamava-se que a reconstrução da cidade deveria obedecer a uma série de regulamentos e normas, a fim de que se constituísse um espaço livre dos miasmas. A mesma preocupação encontra-se nas Memorias das principaes providencias em seus itens I e III, os quais, além de prescreverem cuidados com os habitantes, convocam os magistrados a firmarem leis, e as tropas do reino e da polícia do bairro a executá-las. A saúde, desse modo, convertia-se não apenas em um encargo estatal, mas também em uma obrigação civil.

Por sua vez, no domínio do urbanismo, a cidade transforma-se em protagonista. O projeto de reconstrução de Lisboa foi deflagrador de todo um conjunto de iniciativas, por meio das quais a população assumiria um nível destacado de importância nos cálculos dos governantes. Cada intervenção planejada para a cidade teria como fim seus habitantes: ruas largas, praças, sistema de saneamento, calçamento das vias, arquitetura preventiva para os edifícios. Exemplo disso é a gaiola pombalina, parte de um sistema antissísmico 
constituído por uma estrutura de madeira entrelaçada, formando uma espécie de ossatura interna, disposta geometricamente de modo a formar triângulos, cujo interior era preenchido com alvenaria. Tal estrutura conferiria às paredes a capacidade de dissipar a energia transmitida por ações sísmicas, resguardando a estrutura do prédio (FRANÇA, 1978). Como se vê, os detalhes arquitetônicos foram executados com vistas à forja de uma cidade moderna. Relembrando Foucault (2008), a conformação deste tipo de espacialidade disciplinar deveria contemplar três incumbências: a higiene, o comércio e a vigilância. Mais especificamente, no caso lisboeta, a circulação de coisas e pessoas consistiu na técnica fulcral das ações que visavam remodelar a capital do Reino. Tratou-se, portanto, de incutir um modo distinto de governar tanto a esfera material e política quanto a dimensão subjetiva, em favor da criação de condições propícias para a invenção de uma população apta a habitar uma nova polis.

O terceiro domínio - a educação - amalgama os dois anteriores. A intensa circulação de informações selecionadas, por meio dos impressos, contribuiu para a acareação de dois futuros: um como repetição, outro como renovação. Os ditames que circulavam nos impressos oficiais intentavam expressamente educar os súditos, instruindo-os acerca de uma pletora de hábitos edificantes. Firmando-se como instrumentos estratégicos na condução dos sobreviventes, uma vez que se prestavam a ser elos de comunicação entre o Estado e a população, os impressos deslindavam novas realidades a serem incorporadas, novos modos de se conduzir, novos valores a partir dos quais se nortear. No caos que se seguiu às rupturas provocadas pelo terremoto, os enunciados que circularam na forma de decretos administrativos e/ou de prescrições científicas operaram na forja de determinado presente consignandoo à projeção de um futuro venturoso.

A crescente atenção à educação dos sobreviventes propiciou o deslocamento de um conjunto informe de pessoas para o status de massa populacional passível de ser mensurada, descrita e educada. Assim, os acontecimentos pós-terremoto consistirão em um fator sine qua non da Reforma 
Educacional Pombalina de 1759.

Tal como Azevedo (1976, p. 57) explicita:

\begin{abstract}
Em lugar de um sistema único de ensino, a dualidade de escolas, umas leigas, outras confessionais, regidas todas, porém, pelos mesmos princípios; em lugar de um ensino puramente literário, clássico, o desenvolvimento do ensino científico que começa a fazer lentamente seus progressos ao lado da educação literária, preponderante em todas as escolas; em lugar da exclusividade de ensino de latim e do português, a penetração progressiva das línguas vivas e literaturas modernas (francesa e inglesa); e, afinal, a ramificação de tendências que, se não chegam a determinar a ruptura de unidade de pensamento, abrem o campo aos primeiros choques entre as idéias antigas, corporificadas no ensino jesuítico, e a nova corrente de pensamento pedagógico, influenciada pelas idéias dos enciclopedistas franceses.
\end{abstract}

É certo, pois, que a reorganização educacional proposta por Pombal, lastreada pela influência iluminista (CARVALHO, 1978), findou por promover uma "uma intensificação do pensamento pedagógico e da preocupação com a atitude educativa" (BOTO, 1996, p. 21). Tratava-se, assim, de incitar e regular toda uma série de ações, saberes e modos de existência, desde os aspectos mais estruturais até aqueles mais cotidianos.

A empreitada portuguesa pós-terremoto revela, assim, a efetividade das artes de governar via a produção de um ordenamento populacional condicionado por uma razão educativa, a qual se propunha a alimentar as engrenagens de um processo permanente de correção e de aperfeiçoamento dos modos de vida. Em suma, tratava-se de entabular a equação fazer viver, deixar morrer, tal como Foucault (1999) bem a sintetizou.

Com efeito, pode-se atestar aí os ventos germinais de um acontecimento sócio-histórico capaz, em um só golpe, de pôr em marcha a ruína de uma ordem pregressa e o despontar de uma maneira inédita de levar a cabo o nexo saberpoder-verdade, este a operar laços indissociáveis entre governamento e educação das populações, os quais ainda hoje parecem reverberar em nós. 


\section{REFERÊNCIAS}

ABREU, Jean Luiz Neves. Tratados e construção do saber médico: alguns aspectos dos paratextos nos impressos de medicina luso-brasileiros - século XVIII. Revista Territórios \& Fronteiras, v. 6, n. 2, p. 21-34, 2013.

ALVES, José Augusto dos Santos. O Marquês de Pombal e a mudança de paradigma. Cultura, Lisboa, v. 22, p. 177-192, 2006.

AMADOR, Filomena. O terramoto de Lisboa de 1755: colecções de textos do século XVIII. História, Ciências, Saúde - Manguinhos, Rio de Janeiro, v. 14, n. 1, p. 285-323, jan./mar. 2007.

ARAÚJO, Ana Cristina. Ruína e morte em Portugal no século XVIII: a propósito do terramoto de 1755. Revista de História das Ideias, Coimbra, p. 327-363, 1987.

ARAÚJO, Ana Cristina. The Lisbon earthquake of 1755: public distress and political propaganda. e-journal of Portuguese History, v. 4, n. 1, 2006.

ARAÚJO, Norberto de. Peregrinações em Lisboa. Lisboa: Vega, v. IX, 1939.

ARCHER, Maria. Tipos populares: o moço dos fretes. Revista Municipal, Lisboa, n. 8, p. 53-56, 1941.

AZEVEDO, Fernando de. A transmissão da cultura. São Paulo: Melhoramentos/INL, 1976.

BELO, André. A Gazeta de Lisboa e o terramoto de 1755: a margem do não escrito. Análise Social, Lisboa, v. 34, n. 151-152, p. 619-637, 2000.

BOTO, Carlota. A escola do homem novo: entre o Iluminismo e a Revolução Francesa. São Paulo: Edunesp, 1996.

BOUTARIC, Jean-José. Le tremblement de terre de Lisbonne de 1755.

Médecine de Catastrophe: urgences collectives, v. 1, n. 2, p. 71-76, 1998.

BRAUN, Theodore E. D.; RADNER, John B. The Lisbon earthquake of 1755: representations and reactions. Oxford: Voltaire Foundation, 2005.

CARTA ANÓNIMA. Lisboa, 19 de novembro de 1755. In: SOUSA, Maria Leonor Machado de; NOZES, Judite da Conceição Evaristo (org.). $O$ terramoto de 1755: testemunhos britânicos. Lisboa: Ed. Lisóptima/The British Historical Society of Portugal, 1990. p. 149-153. 
CARVALHO E MELO, Sebastião José de. Memórias secretíssimas do marquês de Pombal e outros escritos. Lisboa: Publicações EuropaAmérica, s/d.

CARVALHO, Laerte Ramos de. As reformas pombalinas da instrução pública. São Paulo: Edusp/Saraiva, 1978.

CARVALHO, Rómulo de. Actividades científicas em Portugal no século XVIII. Évora: Universidade de Évora, 1996.

CHANTAL, Suzanne. Vida quotidiana em Portugal ao tempo do terramoto. Lisboa: Livros do Brasil, 1962.

DEL PRIORE, Mary. O mal sobre a terra: uma história do terremoto de Lisboa. Rio de Janeiro: Top Books, 2003.

DOSSIÊ El terremoto lisboeta de 1755. Cuadernos Dieciochistas, Salamanca, v. 6, 2005. Disponível em: http://revistas.usal.es/index.php/15767914/issue/view/308. Acesso em: 15 jul. 2018.

DYNES, Russell R. The dialogue between Voltaire and Rousseau on the Lisbon earthquake: the emergence of a social science view. International Journal of Mass Emergencies and Disastres, v. 18, n. 1, p. 97-115, mar. 2000.

ECKART, Anselm. Memórias de um jesuíta prisioneiro de Pombal. Braga: Secretariado Nacional do Apostolado a Oração; São Paulo: Edições Loyola, 1987.

FALCON, Francisco Jose Calazans. A época pombalina política econômica e monarquia ilustrada. São Paulo: Ática, 1993.

FARGE, Arlette. Penser et définir l'événement en histoire. Terrain, Paris, n. 38, mar. 2002.

FOUCAULT, Michel. A vida dos homens infames. In: FOUCAULT, Michel. Estratégia, poder-saber. Rio de Janeiro: Forense Universitária, 2006. p. 203-221. (Ditos e Escritos IV).

FOUCAULT, Michel. Do governo dos vivos. São Paulo: WMF Martins Fontes, 2014a.

FOUCAULT, Michel. Em defesa da sociedade. São Paulo: Martins Fontes, 1999.

FOUCAULT, Michel. Entrevista com Michel Foucault. In: FOUCAULT, Michel. Genealogia da ética, subjetividade e sexualidade. Rio de Janeiro: 
Forense Universitária, 2014b. p. 13-34. (Ditos e Escritos IX).

FOUCAULT, Michel. Segurança, território, população. São Paulo: Martins Fontes, 2008.

FOUCAULT, Michel. Subjetividade e verdade. São Paulo: WMF Martins Fontes, 2016.

FOUCAULT, Michel. Vigiar e punir: nascimento da prisão. 14. ed. Petrópolis: Vozes, 1987.

FRANÇA, José Augusto. A reconstrução de Lisboa e a arquitectura pombalina. Lisboa: Instituto de Cultura Portuguesa, 1978.

FRANÇA, José Augusto. Lisboa pombalina e o iluminismo. Lisboa: Horizonte, 1965.

FRANCO, José Eduardo. O “terramoto” pombalino e a campanha de "desjesuitização” de Portugal. Lusitania Sacra, Lisboa, v. 18, p. 147-218, ago. 2016.

FREIRE, Francisco José. Memorias das principaes providencias, que se deraõ no terremoto, que padeceo a Corte de Lisboa no anno de 1755, ordenadas, e offerecidas à Majestade Fidelissima de Elrey D. Joseph I. Nosso Senhor. Lisboa, 1758.

GAZETA DE LISBOA. Lisboa: Officina de Manoel Soares, n. 45, p. 7, 6 nov. 1755a.

GAZETA DE LISBOA. Lisboa: Officina de Manoel Soares, n. 46, p. 9, 13 nov. 1755b.

GONZALBO, Fernando Escalante. Voltaire mira el terremoto de Lisboa.

Cuadernos hispoamericanos, Madri, n. 600, p. 69-82, 2000.

HERNÁNDEZ MARCOS, Maximiliano. Un texto de Immanuel Kant sobre las causas de los terremotos, 1756. Cuadernos Dieciochistas, Salamanca, v. 6, p. 43-77, nov. 2005.

HOUAISS, Antônio. Dicionário Houaiss da língua portuguesa. Rio de Janeiro: Objetiva, 2009.

LEAL, Augusto Soares D’Azevedo Barbosa de Pinho. Portugal antigo e moderno: diccionario geographico, estatistico, chronographico, heráldico, archeologico, historico, biográfico e etymologico de todas as cidades, villas e freguezias de Portugal. v. II. Lisboa: Livraria Editora de Mattos Moreira \& 
Companhia, 1874.

LOUSADA, Maria Alexandre. The police and the uses of urban space. Lisbon, 1780-1830. Apontamentos de Geografia, Lisboa, Centro de Estudos Geográficos da Universidade de Lisboa, 2003.

MALAGRIDA, Gabriel. Juizo da verdadeira causa do terremoto, que padeceo a corte de Lisboa no primeiro de novembro de 1755. Lisboa: Officina de Manoel Soares, 1756.

MARQUES, João Francisco. A acção da Igreja no terramoto de Lisboa de 1755: ministério espiritual e pregação. Lusitania Sacra, Lisboa, v. 18, p. 219-329, ago. 2016.

MENDONÇA, Joachim Joseph Moreira de. História universal dos terremotos que tem havido no mundo, de que ha noticia, desde a sua creação até o seculo presente... Lisboa: Officina de Antonio Vicente da Silva, 1758.

MIDÕES, Miguel. Comunicação de crise no terramoto de 1755. Biblioteca Online de Ciências da Comunicação (Bocc), 2009. Disponível em: http://www.bocc.ubi.pt/pag/midoes-miguel-comunicacao-da-crise-noterramoto.pdf. Acesso em: 15 jul. 2018.

MURY, Paul. Historia de Gabriel Malagrida da Companhia de Jesus, apostolo do Brazil no seculo XVIII estrangulado e queimado no Largo do Rocio de Lisboa aos 21 de setembro de 1761. Lisboa: Livraria Editora de Mattos Moreira \& Cia, 1875.

NOGUERA-RAMÍREZ, Carlos Ernesto. Pedagogia e governamentalidade ou Da Modernidade como uma sociedade educativa. Belo Horizonte: Autêntica, 2011.

PEDEGACHE, Miguel Tibério. Nova, e fiel relaçaõ do terremoto, que experimentou Lisboa, e todo o Portugal no dia $1^{\mathrm{o}}$ de novembro de 1755 . Lisboa: Officina de Manoel Soares, 1756.

RATTON, Jacome. Recordações de Jacome Ratton fidalgo calaveiro da caza real, sobre occurrencias do seu tempo em portugal, durante o lapso de sesenta e tres annos e meio, alias de maiop 1747 a setembro de 1810 que rezidio em lisboa acompanhadas de algumas subsequentes reflexonesns suas, para informaçoens de seus proprios filhos, com documentos no fim. Londres: $\mathrm{H}$. Bryer, 1813. 
ROLLO, Maria Fernanda (org.). História e ciência da catástrofe: $250^{\circ}$ aniversário do terramoto de 1755. Lisboa: Edições Colibri, 2008.

SANCHES, António Nunes Ribeiro. Tratado da conservaçaô da saude dos povos: obra util e igualmente necessaria a os Magistrados, Capitaens Generais, Capitaens de Mar, e Guerra, Prelados, Abbadessas, Medicos, e Pays de Familias: com hum apêndix consideraçoins sobre os Terremotos, com a noticia dos mais consideraveis, de que fas mençaô a Historia, e dos ultimos que se sintiraô na Europa desde o 1 de Novembro de 1755. Paris/Lisboa: Bonardes e Du Beux, 1756.

SANTOS, Antonio Cesar de Almeida. Luzes em Portugal: do terremoto à inauguração da estátua equestre do Reformador. Topoi, Rio de Janeiro, v. 12, n. 22, p. 75-95, jun. 2011.

SANTOS, Guilherme de Oliveira. O Processo dos Távoras. Lisboa: Livraria Portugal, 1979.

SCHWARCZ, Lilia Moritz. A longa viagem da biblioteca dos reis: do terremoto de Lisboa à independência do Brasil. São Paulo: Companhia das Letras, 2002.

SUBTIL, Carlos Lousada; VIEIRA, Margarida. Os Tratados de Polícia, fundadores da moderna saúde pública (1707-1856). Revista de Enfermagem Referência, n. 7, p. 179-187, jul. 2012.

VEIGA-NETO, Alfredo. Governo ou governamento. Currículo sem Fronteiras, v. 5, n. 2, p. 79-85, jul./dez. 2005.

GISELA MARIA DO VAL é doutora em educação pela Faculdade de Educação (Feusp) da Universidade de São Paulo (USP).

E-mail: giselaval@usp.br

(ib) http://orcid.org/0000-0001-8004-0130

JULIO GROPPA AQUINO é professor titular da Faculdade de Educação (Feusp) da Universidade de São Paulo (USP).

E-mail: groppaq@usp.br

(1) http://orcid.org/0000-0002-7912-9303 
Revista História da Educação (Online), 2019, v. 23: e85688 DOI: http://dx.doi.org/10.1590/2236-3459/85688
e-ISSN: 2236-3459 http://seer.ufrgs.br/asphe

Recebido em: 09 de agosto de 2018

Aprovado em: 21 de dezembro de 2018

(c) (i)

Associação Sul-Rio-Grandense de Pesquisadores em História da Educação - Asphe

Artigo de acesso aberto distribuído nos termos de licença Creative Commons. 